\title{
Effect of parents and peer attachment on academic achievement of late adolescent nursing students - A comparative study
}

\author{
Esmat M. Gemeay ${ }^{1,2}$, Eman S. Ahmed ${ }^{* 3}$, Eman R. Ahmad ${ }^{3,4}$, Sana A. Al-Mahmoud ${ }^{4}$ \\ ${ }^{1}$ Tanta University, Tanta, Egypt \\ ${ }^{2}$ King Saud University, Riyadh, Kingdom of Saudi Arabia \\ ${ }^{3}$ Assiut University, Assiut, Egypt \\ ${ }^{4}$ Dammam University, Dammam, Kingdom of Saudi Arabia
}

Received: November 24, 2014

DOI: $10.5430 /$ jnep.v5n6p96
Accepted: March 4, 2015

Online Published: April 13, 2015

\begin{abstract}
Background: Parental and peer attachment have been shown to affect students' academic performance and educational outcomes. Although low attachment to parents and peers was not the single predictor of poor academic performance, strong attachment was found to influence the college students' sense of self and promoted higher self-esteem. Objective: The aim of this study was to investigate the effect of parents' and peer attachment on academic achievement of late adolescent nursing students and compare this effect among Saudi and Egyptian students. In spite of that the total sample were taken from Arab countries, each sample differ in many ways mainly the conservative culture and economic status that was reflected in parent and peer attachment among both countries which foster the researcher to compare it.

Methods: Design: Comparative study design was used for this study should be added here after the methods. Setting: This study was conducted in the Faculty of Nursing- University of Dammam-KSA and Faculty of Nursing-Assuit University-Egypt. Subject: A total subject of 492 nursing students was enrolled in the study (which is representative of the nursing students from level 3 to level 8). Tool: Two tools were used for this study. Tool I: demographic data of the students \& GPA. Tool II: Attachment inventory scale The IPPA consists of 25 items for the mother, 25 items for the father, and 25 items for the peers. A comparative study design was used and a self-report questionnaire with a five point Likert scale response was filled by the study subject.

Results: Attachment of Egyptian students to their peers was significantly higher than Saudi students. A significant subscales of attachment between Saudi and Egyptian students were mother's alienation and peer alienation, high parent and high peer attachment group working more better on academic achievement, however the low parent and peer attachment group wasn't considered as the single predictor of poor academic performance.

Conclusions: Parent's attachment in our study appears to have no effect on academic achievement of both countries. Peer attachment seemed to have a significant effect on academic performance for Egyptian students and not for Saudi students.
\end{abstract}

Key Words: Parents attachment, Peer attachment, Academic achievement, Late adolescent

\section{INTRODUCTION}

Parental and peer attachment affects individuals throughout the entire life. ${ }^{[1]}$ It enhances self-esteem, well-being, em- pathy, core beliefs, as well as relational development and academic development. ${ }^{[2-9]}$ A great deal of research has focused on the influence of attachment and social support

*Correspondence: Eman S. Ahmed; Email: eman.ahmed1@ @ursing.au.edu.eg; http://www.aun.edu.eg/arabic/membercv.php?M_ID=3692 Address: Pediatric Nursing, Faculty of Nursing, Assiut University, Assiut, Egypt. 
on the psychological well-being of adolescents and college adjustment, less attention has focused on parent relations and academic achievement for the college population and in particular, the potential joint effects of parental and peer attachment. ${ }^{[10]}$

While adolescence period distinct by separation individuation, studies suggests that late adolescent college students remain strongly attached to, and influenced by, their parents. ${ }^{[1-14]}$ Understanding how to promote academic achievement among adolescents has long been a challenging task for that several studies have shown that families, schools and peers are all important contextual predictors for adolescent development. ${ }^{[15-17]}$ It was emphasized that parental support promotes higher Grade Point Averages (GPAs). ${ }^{[18]}$ Moreover, the influence of attachment on academic achievement affected by cultural and ethnic differences i.e., collectivist nature may be characterized by reliance on self-discipline as coping strategies. ${ }^{[19,20]}$ Previously, most of studies have focused on relations between students' peer networks and their academic achievement. Some have suggested positive relations between peer acceptance, and academic success among both children and adolescents. ${ }^{[21-23]}$ In the same context, Academic achievement and acceptance by others are usually positively related. On average well-liked students perform better than students low in acceptance. ${ }^{[24,25]}$ However, Bahar ${ }^{[26]}$ concluded perceived social support from a friend had no effect on academic success.

In the same line, several studies have shown that supportive peer attachments in late adolescence are positively correlated with self-esteem, well-being and school achievement. ${ }^{\text {[27-29] }}$ Lisa $^{[30]}$ further emphasized in her thesis that closeness with peers positively influences the target adolescent's academic achievement. Contrasting to a study by Bahar ${ }^{[26]}$ which concluded perceived social support from a friend had no effect on academic success.

Furthermore, Fass and Tubman ${ }^{[6]}$ conducted similar study on college students. Their study revealed that attachment has an important role in adjustment and social transition. Although low attachment to parents and peers was not the single predictor of poor academic performance, strong attachment was found to influence the college students' sense of self and promoted higher self-esteem. As regards studying different attachment styles in diverse cultures and diverse co-cultures, Arbona and Power ${ }^{[31]}$ using highly representative sample found no differences between European and Mexican high school students on anxiety and avoidance attachment type.

Therefore, this study was conducted to compare effect of peer and parental attachment on academic achievement between two different cultures Egypt and Saudi Arabia.
The aim of this study is to:

- Investigate the effect of parents' and peer attachment on academic achievement of adolescent nursing students.

- Compare this effect among Saudi and Egyptian nursing students.

\section{Methods}

\subsection{Research design}

A comparative study design was used for this study.

\subsection{Setting}

This study was conducted in two areas namely: The College of Nursing - University of Dammam - Saudi Arabia and Faculty of Nursing - Assiut University - Egypt. Faculty of nursing Assiut university is a local college of nursing at Assiut at Upper Egypt. It is 4 year study with one year internship in which there are some traditions and customs of conservative nature of Assiut as a part of Upper Egypt especially that concerned with attachment or relations of parents with their daughters and the higher percentage of illiteracy especially among females. However Dammam university is one of governmental Saudi universities at Dammam in the Eastern region of Saudia Arabia. The culture seems more conservative in nature and it has been influenced by the religion of Islam, the role of history, and its traditions which makes it different from other cultures. As it is one with vast economic resources that permit them to hire servants who are mainly responsible for raising their children which further had direct effect on the level of attachment with their daughters. ${ }^{[32]}$

The University of Dammam opened its doors to women and men in 1975 with two pioneering colleges, the college of Medicine and the college of Architecture. Almost four decades later this academic institution has grown into a leading research university with 21 colleges spread throughout the Eastern Province and a student population of over 45,000. As a preeminent research-based institution, the University of Dammam continues to grow and develop, continually assessing and improving its curricula and expanding its academic capabilities in all disciplines, while at the same time engaging the public in addressing environmental and community challenges.

\subsection{Subject}

A total subject of 492 nursing students 238 participants $(48.37 \%)$ represented Saudi Arabia, 254 participants $(51.63 \%)$ represented Egypt. (The subject is representative of the nursing students from level 3 to level 8). The 1st and 2nd 
levels were not included because they were in the preparatory year in another setting. In Assiut First year students was excluded to make the two groups harmonized.

\subsection{Tools of the study}

Two tools were used for this study:

Tool I: Ac structured questionnaire to assess demographic data of the students which includes age, residence, academic level and academic performance in the form of Grade Point Average (GPA) for University of Dammam students - Saudi Arabia, and final evaluation for Assiut University Students Egypt, parental education and occupation, marital status of the students, marital living status of the parents and extent of relation with parents if the student live with one of them in case of divorce.

Tool II: Attachment inventory scale: The Inventory of Parent and Peer Attachment scale (IPPA): It was developed by Armsden \& Greenberg, $1987^{[28]}$ to assess adolescents' perceptions of the positive and negative affective/cognitive dimension of relationships with parents and close friends-particularly how well these figures serve as sources of psychological security. It is the most valid tool used for adolescents and often used for young youth. The IPPA has been widely used in the clinical and developmental child psychology literature, ${ }^{[33-35]}$ Pace, San Martini, and Zavattini ${ }^{[36]}$ conducted a research to evaluate the IPPA's three factor structure. Exploratory factor analyses and confirmatory factor analysis revealed the three factor model had the best fit, although all three dimensions (trust, communication, and alienation) were strongly interrelated. ${ }^{[36]}$

The theoretical framework is attachment theory. It includes three subscales: degree of mutual trust, quality of communication, and extent of anger and alienation. The instrument is a self report questionnaire with a five point Likert scale response format ranges from almost never or never true (1) to almost always or always true (5). The IPPA consists of 25 items for the mother, 25 items for the father, and 25 items for the adolescent. The IPPA is scored by reverse-scoring the negatively worded items and then summing the response values in each section. Two attachments scores, one each for parents and peers, are calculated by adding scores for trust and communication items and subtracting scores for alienation items.

Higher scores indicate higher level of attachment to parents or peers. After summing all items of peer and parents attachment the mean scores were calculated to both parents and peers attachment and GPA was obtained. The scale was not translated into Arabic form, as it is applied to nursing college students.
As all studied subjects taught in English so its valid for students to receive and respond to the questionnaire in English further, the researcher interviewed the students, explained to them what they may not understand.

\subsection{Procedure}

(1) An official permission was obtained from the dean of the Faculty of Nursing in the previous two settings to get the permission for data collection after explaining the purpose of the study.

(2) An informed written consent was obtained from the students before data collection and confidentiality will be considered.

(3) The tool content validity was tested by 5 juries who are experts in the related field.

(4) Internal consistency was measured. The three subscales have demonstrated excellent internal consistency, i.e., Cronbach's alpha coefficients of .91, .91, and .86 for the Parent Trust, Communication, and Alienation subscales, respectively.

(5) The Students' IPPA scores for their perceptions of attachment to parents and peers were divided into two groups (low and high) based on the participant's combined score on the three subscales (Trust, Communication, Alienation) as it is considered low if the parent or peer score level of attachment was less than $50 \%$ and high attachment score was considered if the score level was more than $50 \%$. The two-groups classification variables for parent and peer attachment were then cross-tabulated, creating a typology of eight groups among both countries (Saudi Arabia \& Egypt) ranging from a low peer and low parental attachment group to a high peer and high parental attachment group.

(6) Pilot study: Before embarking on the actual study, a pilot study was carried out on $10 \%$ of the sample (50 students) to assess the tools for clarity and applicability. According to the results of the pilot study, necessary modifications were carried out which were in paraphrasing of some sentences in tool I (level was changed to academic year [In Egypt no levels at the college but academic year]) and these students were excluded from the study subjects.

(7) The researchers interviewed students in break time between lectures and the purpose of the study was shown to them and their written consent was taken to participate in the study.

(8) The sheet was distributed to the students with simple clarification from the researchers. The sheet took about 20 - 25 minutes to be filled by each student.

(9) Academic performance was calculated using GPA in 
University of Dammam and final evaluation in Assiut University. Because the credit hour system was not followed in Faculty of Nursing, Assiut University, GPAs at University of Dammam students was transformed to final grade.

\subsection{Limitations of the study}

(1) A convenient sample of available students was used because random sample will limit the number of the students included in sample.

(2) Credit hour system was used in University of Dammam-College of Nursing and not in Assuit Faculty of Nursing, so final score as excellent, very good, good, fair, and poor was used instead of $\mathrm{A}+, \mathrm{A}$ and so on.

(3) There is difference between range of each final score of Saudi Arabia and Egypt.

\section{RESULTS}

A total of 492 students completed a parental and peer attachment style instrument. From the sample, 238 participants (48.37\%) represented Saudi Arabia, 254 participants (51.63\%) represented Egypt were recruited in the study. Their socio-demographic data were presented in Table 1 which showed the same mean age of both groups. Regarding final score, the majority of Saudi students have very good score compared to about two-fifths of the Egyptian students. The majority of Saudi students live in urban areas compared to only about one-third of the Egyptian students. Percentage of educated mothers was high among mothers of Saudi students than Egyptian ones. Higher percentage of housewives mothers was apparent in Saudi women than Egyptian ones. Higher education was also more among Saudi fathers than Egyptian fathers. It is also shown from the table that about one-third of Saudi students were married compared to only $3.9 \%$ of Egyptian students.

Table 1. Distribution of the nursing college students among Saudi Arabia and Egypt according to their Socio-demographic characteristics

\begin{tabular}{|c|c|c|c|c|}
\hline \multirow{2}{*}{ Item } & \multicolumn{2}{|c|}{ Saudi Arabia $(n=238)$} & \multicolumn{2}{|c|}{ Egypt $(n=254)$} \\
\hline & No. & $\%$ & No. & $\%$ \\
\hline \multicolumn{5}{|l|}{ Age } \\
\hline Mean \pm SD & \multicolumn{2}{|c|}{$20.8 \pm 1.0$} & \multicolumn{2}{|c|}{$20.3 \pm 0.8$} \\
\hline \multicolumn{5}{|l|}{ Academic year } \\
\hline Year two & 89 & 37.4 & 105 & 41.3 \\
\hline Year three & 73 & 30.7 & 67 & 26.4 \\
\hline Year four & 76 & 31.9 & 82 & 32.3 \\
\hline \multicolumn{5}{|l|}{ Final Score } \\
\hline Poor & 0 & 0.0 & 13 & 5.1 \\
\hline Fair & 0 & 0.0 & 9 & 3.5 \\
\hline Good & 42 & 17.6 & 63 & 24.8 \\
\hline Very Good & 156 & 65.5 & 104 & 40.9 \\
\hline Excellent & 40 & 16.8 & 65 & 25.6 \\
\hline \multicolumn{5}{|l|}{ Residence } \\
\hline Countryside & 6 & 2.5 & 163 & 64.2 \\
\hline Urban & 232 & 97.5 & 91 & 35.8 \\
\hline \multicolumn{5}{|l|}{ Mother's education } \\
\hline Illiterate & 36 & 15.1 & 92 & 36.2 \\
\hline Read \& write & 10 & 4.2 & 22 & 8.7 \\
\hline Primary school & 33 & 13.9 & 20 & 7.9 \\
\hline Preparatory school & 45 & 18.9 & 38 & 15.0 \\
\hline Secondary School & 60 & 25.2 & 51 & 20.1 \\
\hline University & 54 & 22.7 & 31 & 12.2 \\
\hline \multicolumn{5}{|l|}{ Mother's work } \\
\hline Housewife & 199 & 83.6 & 190 & 74.8 \\
\hline Employee & 37 & 15.6 & 61 & 24.0 \\
\hline Deceased & 2 & 0.8 & 3 & 1.2 \\
\hline \multicolumn{5}{|l|}{ Father's education } \\
\hline Illiterate & 24 & 10.1 & 34 & 13.4 \\
\hline Read \& write & 2 & 0.8 & 21 & 8.3 \\
\hline Primary school & 23 & 9.7 & 24 & 9.4 \\
\hline Preparatory School & 36 & 15.1 & 51 & 20.1 \\
\hline Secondary School & 72 & 30.3 & 68 & 26.8 \\
\hline University & 81 & 34.0 & 56 & 22.0 \\
\hline \multicolumn{5}{|l|}{ Father's work } \\
\hline Government work & 116 & 48.7 & 146 & 57.5 \\
\hline Un government work & 9 & 3.8 & 2 & 0.8 \\
\hline Others & 102 & 42.9 & 84 & 33.1 \\
\hline Deceased & 11 & 4.6 & 22 & 8.7 \\
\hline \multicolumn{5}{|l|}{ Marital status } \\
\hline Single & 154 & 64.7 & 244 & 96.1 \\
\hline Married & 79 & 33.2 & 10 & 3.9 \\
\hline Divorce & 5 & 2.1 & 0 & 0.0 \\
\hline
\end{tabular}


Table 2 revealed that no significant relation was observed regarding subscales of attachment except for mother and peer alienation among both countries. However, a significant high mean score for peer attachment among Egyptian students rather exceed Saudi students which reflect more attachment of Egyptian students to their peers than Saudi students (43.6
+9.7 versus $41.6+9.7$ respectively)

Figure 1 shows mean attachment scores among Saudi and Egyptian Nursing college students. Mother's, father's and peer attachment score were nearly the same with slight higher mean score among Egyptian students.

Table 2. Distribution of the attachment subscales among Saudi and Egyptian Nursing College students

\begin{tabular}{|c|c|c|c|c|c|c|}
\hline \multirow{3}{*}{ Item } & \multicolumn{4}{|c|}{ Country } & \multirow{3}{*}{$T$} & \multirow{3}{*}{$\boldsymbol{P}$} \\
\hline & \multicolumn{2}{|c|}{ Saudi Arabia } & \multicolumn{2}{|l|}{ Egypt } & & \\
\hline & Mean & SD & Mean & SD & & \\
\hline Mother’s Trust & 40.2 & 6.2 & 39.8 & 6.2 & 0.702 & .483 \\
\hline Mother's Communication & 33.0 & 5.4 & 33.0 & 7.1 & -0.020 & .984 \\
\hline Mother’s Alienation & 15.9 & 5.2 & 14.7 & 5.1 & 2.682 & $.008 *$ \\
\hline Mother's total score & 57.2 & 13.3 & 58.1 & 15.8 & -0.654 & .514 \\
\hline Father’s Trust & 37.5 & 7.1 & 37.6 & 7.3 & -0.054 & .957 \\
\hline Father's Communication & 29.1 & 6.6 & 29.0 & 8.5 & 0.094 & .925 \\
\hline Father’s Alienation & 16.9 & 5.3 & 16.2 & 5.3 & 1.471 & .142 \\
\hline Father's total score & 49.7 & 14.6 & 50.4 & 18.3 & -0.449 & .654 \\
\hline Peer Trust & 37.4 & 5.3 & 38.1 & 5.3 & -1.466 & .143 \\
\hline Peer Communication & 26.7 & 4.4 & 26.7 & 4.8 & 0.086 & .931 \\
\hline Peer Alienation & 22.5 & 4.5 & 21.2 & 3.7 & 3.577 & $.000 *$ \\
\hline Peer total score & 41.6 & 8.6 & 43.6 & 9.7 & -2.436 & $.015 *$ \\
\hline
\end{tabular}

Note. Independent $t$-test used; * There is a significant statistically difference at $p<.01$.

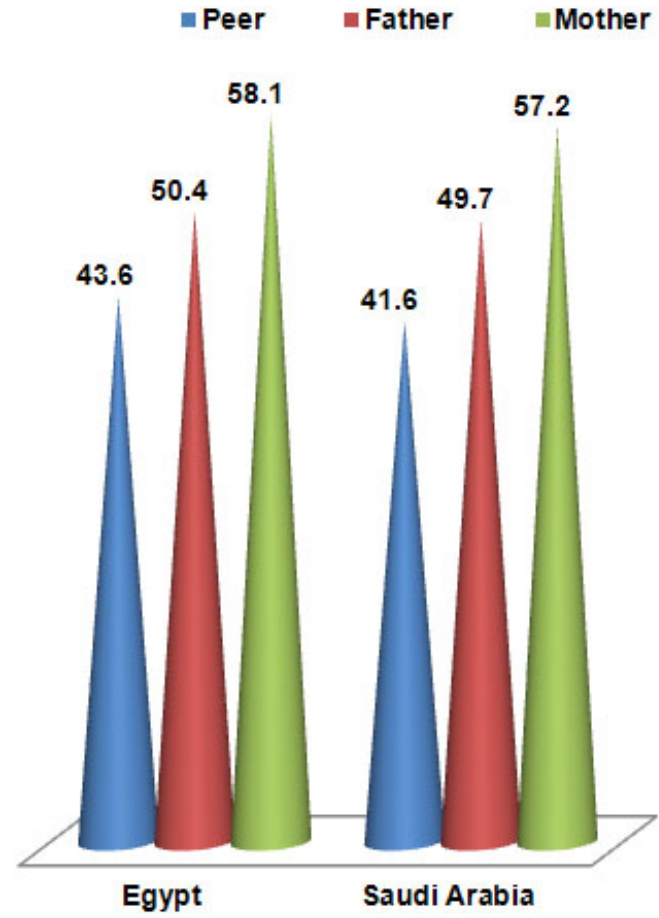

Figure 1. Distribution of the mean attachment scores among Saudi and Egyptian nursing college students

Table 3 revealed no significant relation between low parent and peer attachment among both countries. However a significant relation between high parents and peer score according to each country was noticed. In general, comparison of student groups among Saudi Arabia and Egypt country based on levels of attachment to parents and peers revealed that the High-High attachment group was better functioning than the low-low group without significant difference.

Figure 2 illustrates distribution of student groups to their level of parent and peer attachment with their final score among Saudi nursing college students with higher very good and good scores among high- high than low-low group.

Figure 3 demonstrates distribution of student groups to their level of parent and peer attachment with their final score among Egyptian Nursing college students with higher excellent score among high- high than low- low group.

Table 4 and Figure 4 delineate that parent attachment had no significant effect on students' academic achievement measured by final score. However, the minority of Egyptian students who have high parent attachment score had poor and fair final score. As regards the peer attachment score and its effect on academic achievement, no significant difference was apparent between low and high peer attachment score and the final students score in Saudi Arabia and Egypt. Furthermore, as considering the comparison between the two countries regarding parent attachment score, no significant difference was shown between low parent attachment score but a significant difference was apparent regarding high at- 
tachment score and the final students' score. As regards the peer attachment score, a significant difference was observed among low and high score and the final Egyptian scores as the vast minority among the Egyptian students who have high peer attachment score obtain poor and fair score.

Table 3. Relationship between parent and peer attachment scores among Saudi and Egyptian nursing college students

\begin{tabular}{|c|c|c|c|c|c|c|c|c|c|c|}
\hline \multirow{4}{*}{$\begin{array}{l}\text { Peer score } \\
\text { level }\end{array}$} & \multicolumn{10}{|c|}{ Parents score level } \\
\hline & \multicolumn{5}{|c|}{ Saudi Arabia } & \multicolumn{5}{|c|}{ Egypt } \\
\hline & \multicolumn{2}{|c|}{ Low } & \multicolumn{2}{|c|}{ High } & \multirow{2}{*}{$\boldsymbol{P}$} & \multicolumn{2}{|c|}{ Low } & \multicolumn{2}{|c|}{ High } & \multirow{2}{*}{$\boldsymbol{P}$} \\
\hline & No. & $\%$ & No. & $\%$ & & No. & $\%$ & No. & $\%$ & \\
\hline Low & 3 & 100.0 & 185 & 80.4 & .524 & 3 & 50.0 & 159 & 66.5 & .329 \\
\hline High & 0 & 0.0 & 45 & 19.6 & & 3 & 50.0 & 80 & 33.5 & \\
\hline Total & 3 & 100.0 & 230 & 100.0 & & 6 & 100.0 & 239 & 100.0 & \\
\hline$P$ & $.133^{*}$ & & & & & .001 & & & & \\
\hline
\end{tabular}

* Relation between Low parents and low peer score according to each country; ** Relation between High parents and peer score according to each country.

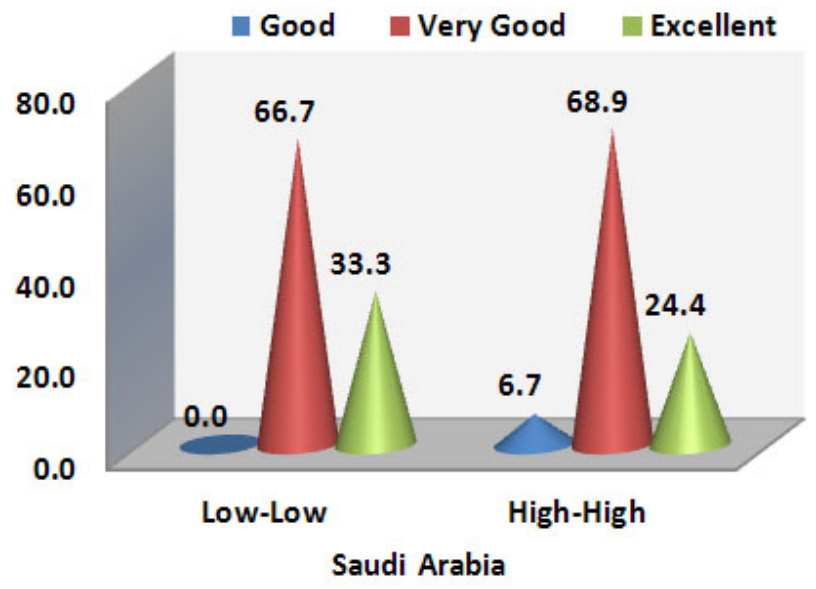

Figure 2. Distribution of the students groups according to their level of parent and peer attachment by their final score among Saudi nursing college students

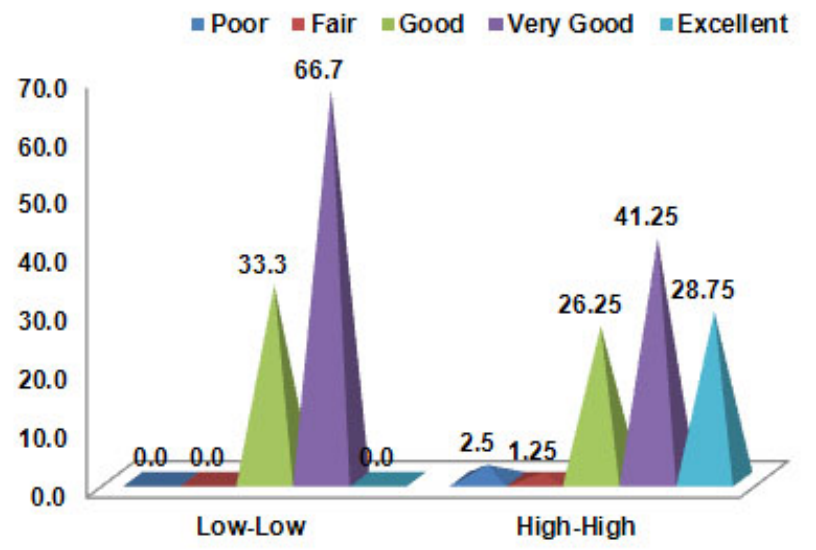

Figure 3. Distribution of the students groups according to their level of parent and peer attachment by their final score among Egyptian nursing college students

Table 5 revealed that residence of the Saudi students affect significantly on the academic achievement as the vast major- ity of them were living in urban area which is considered as interfering factor with the attachment. Furthermore, peer attachment score interfere and affect significantly on academic achievement among Egyptian students; and no significant interference was found regarding socio-demographic data, current living and parent's status or parent attachment score.

\section{Discussion}

The present study aimed to assess the effect of parental and peer attachments on adolescents' academic achievement and compare that among Saudi and Egyptian students. Demographic data about participants from the two countries helps to provide deeper understanding for a more accurate interpretation of the results, revealing that participants from each sample were different in many ways with respect to age, final score, place of residency, level of education and work for their mother and father and also for the students' marital status, however, no significant correlation was observed for the different students' academic year. Furthermore, a significant difference was observed regarding students living status and relation to their mother and no significant difference between both groups related to the relation with their father among each country (see Table 1). In this context, research on the influence of parental attachment on academics has also revealed cultural and ethnic differences possibly associated with the collectivist nature of the culture or the adolescent's reliance on self-discipline coping strategies. ${ }^{[19,20]}$

The present study revealed that late adolescent college students' levels of perceived parental and peer attachment showed substantial variability, and there was a significant association between the two types of attachment. Furthermore, Final academic score was statistically significant between Saudi and Egyptian students with no one Saudi student had poor or fair score and higher number of Saudi students had very good score (see Figures 2 and 3). This might be of 
many reasons among which are suggestion of the easiness and simplicity of courses and exams in Saudi Arabia or might be because of less bureaucratic system of scoring in Saudi Arabia.

Regarding parental education, it was found that fathers and mothers of Saudi students had higher percentage of university education than those of Egyptian students (see Table 1), which reflects the higher socio-economic conditions of Saudi students and that the educated Saudi parents encouraged their daughters to join the university. Despite of low percent of highly educated Egyptian parents, they are keen to complete higher education of their daughters. This is in agreement with the widely recognized belief that students' academic achievement and school disengagement are affected by their parents' education level. Several researchers have indicated that parents' education predicted more of the variability in school achievement than other family demographic characteristics. ${ }^{[37,38]}$

Table 4. Distribution of the students final score according to the parent and peer attachment score

\begin{tabular}{|c|c|c|c|c|c|c|c|c|c|c|c|}
\hline \multirow{3}{*}{ Final score } & & \multicolumn{5}{|c|}{ Parents attachment score } & \multicolumn{5}{|c|}{ Peer attachment score } \\
\hline & & \multicolumn{2}{|c|}{ Low } & \multicolumn{2}{|c|}{ High } & \multirow{2}{*}{$\boldsymbol{P}$} & \multicolumn{2}{|c|}{ Low } & \multicolumn{2}{|c|}{ High } & \multirow{2}{*}{$\boldsymbol{P}$} \\
\hline & & No. & $\%$ & No. & $\%$ & & No. & $\%$ & No. & $\%$ & \\
\hline \multirow{6}{*}{ Saudi Arabia } & Poor & 0 & 0 & 0 & 0 & \multirow{6}{*}{.6} & 0 & 0 & 0 & 0 & \multirow{6}{*}{.207} \\
\hline & Fair & 0 & 0 & 0 & 0 & & 0 & 0 & 0 & 0 & \\
\hline & Good & 0 & 0.0 & 38 & 16.5 & & 37 & 19.4 & 5 & 10.6 & \\
\hline & Very Good & 2 & 66.7 & 153 & 66.5 & & 125 & 65.4 & 31 & 66.0 & \\
\hline & Excellent & 1 & 33.3 & 39 & 17.0 & & 29 & 15.2 & 11 & 23.4 & \\
\hline & Total & 3 & 100.0 & 230 & 100.0 & & 191 & 100.0 & 47 & 100.0 & \\
\hline \multirow{6}{*}{ Egypt } & Poor & 1 & 16.7 & 12 & 5.0 & \multirow{6}{*}{.3} & 10 & 5.9 & 3 & 3.5 & \multirow{6}{*}{.723} \\
\hline & Fair & 1 & 16.7 & 8 & 3.3 & & 7 & 4.1 & 2 & 2.4 & \\
\hline & Good & 1 & 16.7 & 59 & 24.7 & & 41 & 24.3 & 22 & 25.9 & \\
\hline & Very Good & 2 & 33.3 & 102 & 42.7 & & 71 & 42.0 & 33 & 38.8 & \\
\hline & Excellent & 1 & 16.7 & 58 & 24.3 & & 40 & 23.7 & 25 & 29.4 & \\
\hline & Total & 6 & 100.0 & 239 & 100.0 & & 169 & 100.0 & 85 & 100.0 & \\
\hline$P$ & & .691 & & .001 & & & .001 & & .024 & & \\
\hline
\end{tabular}

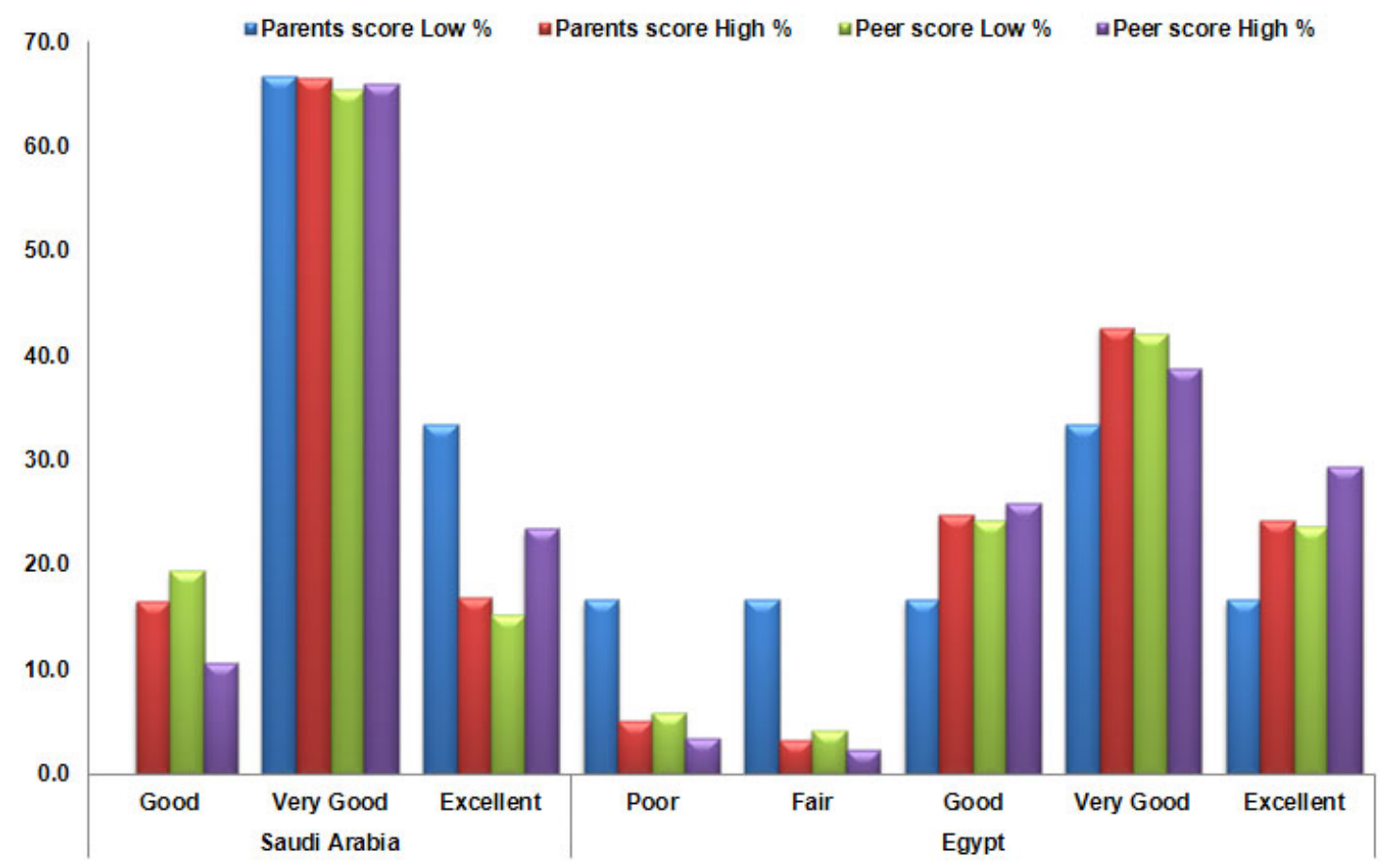

Figure 4. Distribution of the students final score according to the parent and peer attachment score 
Table 5. Multiple regression model: Students' college final score predicted by demographic, parents' status and attachment variables

\begin{tabular}{llllll}
\hline \multirow{2}{*}{ Items } & Saudi Arabia & & & Egypt & \\
\cline { 2 - 3 } \cline { 5 - 6 } & $\boldsymbol{T}$ & $\boldsymbol{P}$ & & $\boldsymbol{T}$ \\
\hline Residence & -3.732 & .000 & -0.321 & .748 \\
Mother's education & 0.376 & .707 & -0.022 & .982 \\
Mother's work & 1.404 & .162 & -0.818 & .414 \\
Father's education & -0.515 & .607 & 1.803 & .073 \\
Father's work & -0.454 & .650 & -0.097 & .923 \\
Marital status & 0.715 & .475 & 0.633 & .528 \\
Current living status & -1.285 & .200 & -1.668 & .097 \\
Parents' status & 0.183 & .855 & -0.497 & .620 \\
Parent attachment score & 0.288 & .773 & 0.292 & .771 \\
Peer attachment score & 0.161 & .873 & 2.160 & .032 \\
\hline
\end{tabular}

In addition, more Saudi mothers were housewives compared to Egyptian mothers with statistically significant differences (see Table 1). This reflects the nature of Saudi culture which observes the intermingling between males and females in the workplace which might have an effect on limiting the job opportunities of Saudi females. Also some families (fathers or husbands) prefer to have the female in their families stay at home and do not work even if they are educated. In addition, it was noticed that females have less education level compared to males' Saudi people in the studied population.

On studying the effect of parents and peer attachment on academic level, it was found although low parent low peer had higher very good score, high parent high peer had higher excellent scores among Egyptian nursing students, and the effect among Saudi nursing students was not clear enough (see Figure 4). This is in accordance with Fass and Tub$\operatorname{man}^{[6]}$ who reported that low attachment to parents and peers was not the single predictor of poor academic performance. Furthermore, the present study found that those who have strong attachment to their parents had low attachment to their peer among Saudi and Egyptian students.

The study revealed that the only statistically significant attachment subscales among Saudi and Egyptian nursing students were mother's alienation and peer's alienation with higher mean score of mother and peer alienation among Saudi nursing students (see Table 2). This may be explained by the observed high dependency on helpers/housekeepers in raising the children which might cause less attention and attachment of Saudi mothers to their children. Further, peer alienation mean score was also higher among Saudi nursing students may be because of conservative nature of Saudi culture which gives less trust to peers.

Although adolescents are still close to their parents, they spend increasingly more time with their friends. Their physical and emotional dependence on their parents decreases and they move closer to the peer group. ${ }^{[39]}$

The present study provides insights into the important role of peers in influencing academic achievement especially among the Egyptian nursing college students compared to Saudi students, as the mean peer attachment score was 43.6 versus 41.6, respectively as shown in Table 2. This finding suggests that peers are in a position to improve the college performance of their adolescents by providing them with support as the vast minority among the Egyptian students who have high peer attachment score obtain poor and fair score. This finding reflects the nature of Egyptians toward others and the cultural opening of the relations among peers. This finding was consistent with Holahan, Cotterell, and Kupersmidt et al. ${ }^{[21-23]}$ who have focused in their studies on relations between students' peer networks and their academic achievement. They suggested positive relations between peer acceptances/ peer support and academic success among both children and adolescents. In addition, Bean and Hearn ${ }^{[40,41]}$ found that positive interaction with friends was a significant determinant of college satisfaction.

This study found evidence in favor of Nickerson and $\mathrm{Na}$ gle, ${ }^{[29]}$ closeness with peers positively influences the target adolescent's academic achievement. Contrasting to a study by Bahar ${ }^{[26]}$ which concluded perceived social support from a friend had no effect on academic success.

Also Pearson and Child ${ }^{[42]}$ found that attachment to parents and peers is a major component in social competence and adjustment during college years. Moreover, Fass and Tub$\operatorname{man}^{[6]}$ found that low attachment to both parents and peers did not automatically place students at risk for academic failure or social incompetence. They warned however, that low attachment may adversely impact future career choices, employment and social domain due to a low sense of selfesteem. 
In multiple regression analysis, it revealed the only significant variable on academic achievement was residence for Saudi students and peer attachment for Egyptian students. This can be explained that the majority of Saudi students live in urban areas which perhaps facilitate learning through the availability of web or civilized (modern) life style save time of transportation, or feeling of satisfaction associated with urban living which may affect academic achievement. Regarding Egyptian sample, we have to emphasize that the majority of students are coming from countryside field in which low level of education were apparent that explains the low percentage of education and employment among their parents. This finding is considered as interfering factor with the attachment (see Table 5).

\section{Conclusion}

Based on the results of this study, it can be concluded that parent's attachment in this study appears to have no effect on academic achievement of both countries however, total peer attachment score was significantly higher among Egyptian students compared to Saudi students, further, high parent and high peer group working more better on academic achievement, however the low parent and peer attachment group wasn't considered as the single predictor of poor academic performance. Regarding subscales of attachment, a significant increase in subscales of attachment appears in mothers and peers alienation among Saudi students compared to Egyptian students.

\section{Recommendations}

- Use observational or behavioral assessments would have been helpful in validating self-reported GPAs among Saudi students and final score for Egyptian students for statistical analysis. Health education programs may be needed to explain attachment of parents to their daughters which is limited because of the cultural constrains in Upper Egypt, further, peer attachment should be emphasized among the Saudi culture. These Program sessions could include students and parents discussing how can students maintain positive relations with parents and family while gaining independence and taking on more personal responsibility as they enter college. Our college can assist with these efforts by holding parent orientation sessions, sponsoring student-parent events, and providing resources for parents such as websites, parent policy handbooks, and a clear listing of appropriate personnel to contact to resolve specific issues. Open communication and a positive partnership between parents and university personnel may provide an integrated support system that facilitates college student success.

- Further research is needed to assess the effect of other factors on academic achievement as social support, parental monitoring and academic advising services. Further research is needed to assess the effect of parental and peer attachment on self-esteem and social adjustment of students.

\section{CONFlicts of INTEREST Disclosure}

The authors declare that there is no conflict of interest statement.

schools. 2002; 39(5): 561-573.

\section{REFERENCES}

[1] Roisman GI, Madsen SD, Hennighausen KH, et al. The coherence of dyadic behavior across parent-child and romantic relationships as mediated by the internalized representation of experience. On assimilating identities to the self: a self-determination theory perspective on internalization and integrity within cultures. In: Bester G. (2007) Personality development of the adolescent: peer group versus parents. South African Journal of Education. 2001; 177-190.

[2] Blissett J, Walsh J, Harris G, et al. Different core beliefs predict paternal and maternal attachment representations in young women. Clinical Psychology and Psychotherapy. 2006; 13: 163-171. http://dx.doi.org/10.1002/cpp. 482

[3] Bowlby J. Attachment and Loss, Volume 1, Attachment. New York: Basic Books, 1969.

[4] Bowlby J. Attachment and loss: Volume 2, Separation. New York: Basic Books, 1973.

[5] Bowlby J. Attachment and loss: Volume 3, Loss. New York: Basic Books, 1980.

[6] Fass ME, Tubman JG. The influence of parental and peer attachment on college students 'academic achievement, psychology in the
7] Kenny ME, Sirin SR. Parental attachment, self-worth, and depressive symptoms among emerging adults. Journal of Counseling and Development. 2006; 84: 61-71. http://dx.doi.org/10.1002/j.155 6-6678.2006.tb00380.x

[8] Laible DJ, Carlo G, Roesch SC. Pathways to self-esteem in late adolescence: The role of parent and peer attachment, empathy, and social behaviors. Journal of Adolescence. 2004; 27: 703716. PMid:15561312 http://dx.doi.org/10.1016/j.adolesc ence. 2004.05.005

[9] Wilkinson RB. The role of parental and peer attachment in the psychological health and self-esteem of adolescents. Journal of Youth and Adolescence. 2004; 33: 479-493. http://dx.doi .org/10.10 23/B : JOYO. 0000048063.59425 .20

[10] Schwanz, Kerry A, et al. College Students' Perceptions of Relations with Parents and Academic Performance. American Journal of Educational Research. 2014; 2(1): 13-17. http://dx. doi.org/10.12 691/education-2-1-3

[11] Hoffman J. Psychological separation of late adolescents from their parents. Journal of Counseling Psychology. 1984; 31: 170-178. 
http://dx.doi.org/10.1037/0022-0167.31.2.170

[12] Bank BJ, Slavings RL, Biddle BJ. Effects of peer, faculty, and parental influences on students' persistence. Sociology of Education. 1990; 63: 208-225. http://dx.doi .org/10.2307/2112838

[13] Kenny ME. College seniors' perceptions of parental attachments: The value and stability of family ties. Journal of College Student Development. 1990; 31: 39-46.

[14] Kenny ME, Donaldson GA. Contributions of parental attachment and family structure to the social and psychological functioning of first-year college students. Journal of Counseling Psychology. 1991; 38: 479-486. http://dx.doi.org/10.1037/0022-0167.38.4 .479

[15] East PL, Rook KS. Compensatory patterns of support among children's peer relationships. A test using school friends, non-school friends, and siblings. Development Psychology. 1992; 28: 163-172. PMid:25067850 http://dx.doi.org/10.1037/0012-1649.28 .1 .163

[16] Eccles J, Roeser R. Schools, academic motivation, and stageenvironment fit. In R. Lerner, \& L. Steinberg, Handbook of Adolescent Psychology Third Edition Hoboken, New Jersey: John Wiley \& Sons, Inc. 2009; 1: 404-434.

[17] Ma L, Phelps E, Lerner JV, et al. Academic competence for adolescents who bully and who are bullied: Findings from the 4-H study of positive youth development. Journal of Early Adolescence. 2009; 29(6): 862-897. http://dx.doi.org/10.1177/0272431 609332667

[18] Moss E, St.-Laurent D. Attachment at school age and academic performance. Developmental Psychology. 2001; 37: 863-874. http://dx.doi.org/10.1037/0012-1649.37.6.863

[19] Harrison AO, Wilson MN, Pine CJ, et al. Family ecologies of ethnic minority children. Child Development. 1990; 61: 347-362. http://dx.doi.org/10.2307/1131097

[20] Liang B, Bogat GA. Culture, control, and coping: New perspectives on social support. American Journal of Community Psychology. 1994; 22: 123-147. http://dx.doi.org/10.1007/BF02506820

[21] Holahan CJ, Valentiner DP, Moos RH. Parent support and psychological adjustment during the transition to young adulthood in a college sample. Journal of Family Psychology. 1994; 2: 215-223. http://dx.doi.org/10.1037/0893-3200.8.2.215

[22] Cotterell JL. The relation of attachments and supports to adolescent well-being and school adjustment. Journal of Adolescent Research. 1992; 7: 28-42. http://dx.doi.org/10.1177/0743554892710 03

[23] Kupersmidt JB, Coie JD, Dodge KA. The role of poor peer relationships in the development of disorder. In S.R. Asher \& J.D. Coie (Eds.), Peer rejection in childhood. Cambridge studies in social and emotional development. New York: Cambridge University Press; 1990; 274-305. http://dx.doi .org/10.1016/S0022-4405(05 ) $80003-2$

[24] Frentz C, Gresham FM, Elliot SN. Popular, controversial, neglected, and rejected adolescents: Contrasts of social competence and achievement difference. Journal of School Psychology. 1991; 29: 109-120.

[25] Meijs N, Cillessen A, Scholte R, et al. Social Intelligence and Academic Achievement as Predictors of Adolescent Popularity. Youth Adolesc. 2010 Jan; 39(1): 62-72. PMid:20091217 http://dx.doi .org/10.1007/s10964-008-9373-9

[26] Bahar $\mathrm{H}$. The effects of gender, perceived social support and sociometric status on academic success. Procedia Social and Behavioral Sciences. 2010; 2: 3801-3805. http://dx.doi.org/10.1016/j .sbspro.2010.03.593
[27] Wentzel K, Battle A, Russell S, et al. Social supports from teachers and peers as predictors of academic and social motivation. Contemporary Educational Psychology. 2010; 35: 193-202. http: //dx.doi.org/10.1016/j.cedpsych.2010.03.002

[28] Armsden G, Greenberg MT. The Inventory of Parent and Peer Attachment: Individual differences and their relation to psychological well-being in adolescence. Journal of Youth and Adolescence. 1987; 16: 427-454. PMid:24277469 http://dx.doi.org/10.1007/B F02202939

[29] Nickerson A, Nagle R. The influence of parent and peer attachments on life satisfaction in middle childhood and early adolescence. Social Indicators Research. 2004; 66: 35. http://dx.doi.org/10.1023 /B:SOCI . 0000007496.42095.2c

[30] Lisa Mae Ryherd. Predictors of academic achievement: The role of older sibling and peer relationship factors; Iowa State University; 2011.

[31] Arbona C, Power TG. Parental attachment, self-esteem, and antisocial behaviors among African American, European American, and Mexican American adolescents. Journal of Counseling Psychology. 2003; 50: 40-51. http://dx.doi.org/10.1037/0022-0167.50 .1 .40

[32] Al-Mahmoud S. The commitment of Saudi nursing students to nursing as a profession and as a career. Life Science Journal. 2013; 10 (2).

[33] Abela R, Hankin B, Haight E, et al. Interpersonal vulnerability to depression in high-risk children: The roe of insecure attachment and reassurance seeking. Journal of Clinical and Adolescent. Psychology. 2005; 34(1): 182-192.

[34] Costa NM, Weems CF. Maternal and child anxiety: Do attachment beliefs orchildren's perceptions of maternal control mediate their association? Journal of Social Development. 2005; 14(4): 574-590. http://dx.doi.org/10.1111/j.1467-9507.2005.00318.x

[35] Parade SH, Leerkes EM, Blankson AN. Attachment to parents, social anxiety, and close relationships of female students over the transition to college. Journal of Youth and Adolescence. 2010; 39: 127-137. PMid:20084559 http://dx.doi.org/10.1007/s10964-009-9 396- $\mathrm{x}$

[36] Pace CS, San MP, Zavattini GC. The factor structure of the Inventory of parent and peer attachment (IPPA): A survey of Italian adolescents. Personality and Individual Differences. 2011; 51: 83-88. http://dx.doi.org/10.1016/j.paid.2011.03.006

[37] Dornbusch M, Ritter L, Mont-Reynaud R, et al. Family decisionmaking and academic performance in a diverse high school population. Journal of Adolescent Research. 1990; 5: 143-160. http: //dx.doi.org/10.1177/074355489052003

[38] Stevenson DL, Baker DP. The family-school relation and the child's school performance. Child Development. 1987; 58: 1348-1357. PMid:3665650 http://dx.doi.org/10.2307/1130626

[39] Ryan RM, Deci EL. On assimilating identities to the self: a selfdetermination theory perspective on internalization and integrity within cultures. In: Leary MR \& Tangney JP. Handbook of self and identity. New York: Guilford; 2003.

[40] Bean JP. The application of a model of turnover in work organization to the student attrition process. Review of higher education. $1983 ; 6$ : 129-148.

[41] Hearn JC. Determinants of College students' overall evaluations of their academic programs. Review of higher education. 1985; 23 : 413-437.

[42] Pearson JC, Child JTA. Cross cultural comparison of parental and peer attachment styles among adult children from the United States, Puerto Rico, and India. WCA 2007 Conference, Brisbane; 2007. 